\title{
The cultural competence learning needs of migrant nurses: A literature review
}

\author{
Fatima Al-Komah*1, Fadi Khraim², Daniel Forgrave ${ }^{2}$, Rawia Saabneh ${ }^{3}$ \\ ${ }^{1}$ Department of Nursing, Hamad Medical Corporation, Qatar \\ ${ }^{2}$ University of Calgary, Qatar \\ ${ }^{3}$ Department of Nursing Education, Hamad Medical Corporation, Qatar
}

Received: August 6, 2019

DOI: $10.5430 /$ ijh.v6n1p48
Accepted: December 29, 2019 Online Published: February 25, 2020

URL: https://doi.org/10.5430/ijh.v6n1p48

\begin{abstract}
Introduction: Migrant nurses need to provide healthcare that is culturally appropriate to the host population. The aim of this literature review is to identify the cultural competence learning needs of migrant nurses that would assist in their transition to the host country.

Methods: A literature review was carried out according to Cronin, Ryan, and Coughlan's (2008) framework. This review included 13 articles published between 2008 and 2018 that discussed cultural competence training for migrant nurses.

Results: Migrant nurses' learning needs fall into four themes: communication, religion and spirituality, customs, and work environment.

Discussion: Language barrier and unfamiliarity with a patient's religion and customs are the main causes of most misunderstandings in the workplace and result in a lack of perceived quality of care. Moving to a different work environment often involves taking on a new role and learning about a new type of organizational structure.
\end{abstract}

Key Words: Cultural competence, Migrant nurses, Education program, Transition

\section{INTRODUCTION}

Increased demand for a nursing workforce has led many nurses to migrate and pursue international employment. ${ }^{[1]}$ Once nurses arrive in a new country, they are expected to provide culturally competent care for clients from different cultures. Cultural competence is a concept originally conceived by Leininger in the 1950s; it encourages people to understand and value other cultures so that people can live and work together with positive outcomes for everybody. ${ }^{[2]}$

\section{Background and significance}

Cultural competence is diligence in attaining skills that enable healthcare providers to deliver care that puts patients' cultures within the context of care. ${ }^{[2]}$ When first discussing the importance of cultural diversity, Leininger argued that nurses must focus on the application of culturally competent healthcare in order for them to become transcultural nurses. Leininger believed that cultural competence involves studying and linking the emic (local culture and lifeways) and the etic (outsiders' knowledge) in order to offer holistic care that is culturally specific. ${ }^{[1,2]}$ Gaining this awareness of one's own culture followed by awareness of other cultures is a lifelong journey ${ }^{[3]}$ which can have an impact on healthcare practice. $^{[4]}$

Nursing care that is culturally competent improves the satis-

*Correspondence: Fatima Al-Komah; Email: fatima.alkomah@ucalgary.ca; Address: Hamad Medical Corporation, Qatar. 
faction of patients while enhancing the quality of care and reducing disparities in healthcare among culturally different groups. ${ }^{[3,5-7]}$ Cultural competence also helps to increase health literacy, leads to an improved compliance to treatments, and reduces medication errors. ${ }^{[4,5]}$ Cultural competence should be part of a healthcare facility's business strategy to inform policymaking and administration. ${ }^{[6,8]}$ Truong and her colleagues also stated that cultural competence in healthcare could enhance equity by offering treatments in line with patients' cultural beliefs. ${ }^{[8]}$ Leininger argued that cultural competence in nursing is even more critical due to the rise in global migration and accompanying racism, and a move from hospital to community settings in healthcare. ${ }^{[2]}$ However, it is often difficult for healthcare givers working in a western dominated system to offer culturally competent healthcare to patients who have different cultural beliefs. ${ }^{[9]}$ Migrant nurses are those who travel outside their own countries to practice nursing. ${ }^{[10]}$ This literature review aims to assess the learning needs that are essential for migrant nurses' attainment of cultural competence.

\section{Methods}

In order to examine cultural competence learning needs among nurses who migrate to work in other countries, a literature review was conducted using the framework by Cronin, Ryan, and Coughlan. ${ }^{[11]}$ The research question that guided the process of the literature review was "What are the learning needs of migrant nurses to improve their cultural competency?" The literature review process involves searching databases for pertinent literature, then analyzing, synthesizing, and writing the findings. ${ }^{[11]}$

\subsection{Search processes}

The following databases were searched: the Cumulative Index to Nursing and Allied Health (CINHAL), Medline, Academic Search Complete, and Education Resources Informa- tion Center (ERIC). The key terms used in the search were: cultural competence*, cultural awareness, cultural sensitivity, cultural diversity, foreign nurses, foreign nurse*, migrant nurse*, expatriate nurse*, international nurse*, international educated nurse*, overseas nurse*, foreign educated nurse* development, staff program*, and transitional programs. The Boolean operators AND OR were also used to narrow or broaden this search.

\subsection{Evaluation and critical appraisal}

The search process yielded 1,227 articles. Duplicate articles were removed before reviewing the articles' titles, abstracts, and full texts based on inclusion and exclusion criteria (see Table 1). This process yielded 12 articles. An additional article was included based upon a review of the reference lists of these 12 articles, resulting in 13 articles being included in this review (see Figure 1). Eleven of these articles were qualitative and two were quantitative. The quality of the articles was assessed using the Mixed Methods Appraisal Tool-v.2011. ${ }^{[12]}$ Its quality scoring is based on ratings for a 4-item questionnaire for the particular study methodology. Each item is rated at $25 \%$ for a total of $100 \%$ for all items. A $100 \%$ indicates best rating of article quality. ${ }^{[12]}$ Quality appraisals are shown in Appendix.

\subsection{The article review process}

The chosen articles were read several times by the author with a focus on the results in order to extract the major themes. Each article was categorized into a matrix to allow for easy cross-reference and comparison of information. The matrix included: (a) journal citation and place and date of data collection, (b) purpose, (c) sample size, (d) study design and sample characteristics, (e) type of model and/or training, (f) source or instruments, (g) results, and (h) strengths and limitations.

Table 1. The inclusion and exclusion criteria in the literature search

\begin{tabular}{ll}
\hline Inclusion Criteria & Exclusion Criteria \\
\hline Original peer reviewed studies & Secondary sources or non-peer reviewed studies \\
Studies written in English & Studies not written in English \\
Studies published from 2008 to 2018 & Studies published before 2008 \\
Studies of nursing staff & Studies of non-nursing staff \\
Studies about cultural competency training for migrant nurses & Studies that were not about cultural competency \\
\hline
\end{tabular}

\section{RESUlts}

The 13 studies included in this literature review were conducted in eight different countries with sample sizes ranging from one to 584 participants. Three concerned the improve- ment of culturally competent nursing care of migrant nurses at a university hospital; another assessed non-Muslim nurses' knowledge of Muslim women's childbearing practices; the third looked at the difficulties associated with recruiting 
nurses from abroad. One study conducted in Saudi Arabia and the UAE aimed to understand the degree of cultural shock nurses have when they start to work in Saudi Arabia or the UAE and their lack of cultural or religious knowledge. Five studies took place in the USA to examine the integration of foreign and local nursing staff; one examined the lived experience of a Taiwanese nurse; one looked at whether international nurses working in the USA could communicate with cultural competence; one examined the social requirements of foreign nurses; one looked at the challenges faced by migrant nurses. One study that was conducted in Chile looked at the cultural experiences faced by migrant nurses. Two studies were done in the UK: one examined how cultural differences affect patient care and the other looked at the experience of nurses recruited from India who participated in an overseas nurses' program. A study done in Canada looked at how well foreign nurses performed in a workplace with a different culture.

People who move to another country for work often experience culture shock, which is described as "anxiety that results from losing the familiar signs and symbols of social intercourse, and their substitution by other cues that are strange". ${ }^{[13]}$ Culture shock is associated with a lack of knowledge about a culture such as its language, religion, food, family, and work life, ${ }^{[14]}$ which may result in feelings of helplessness and depression. ${ }^{[13]}$ Four main themes related to the cultural competence learning needs of migrant nurses emerged from this literature review: communication, religion and spirituality, customs, and work environment.

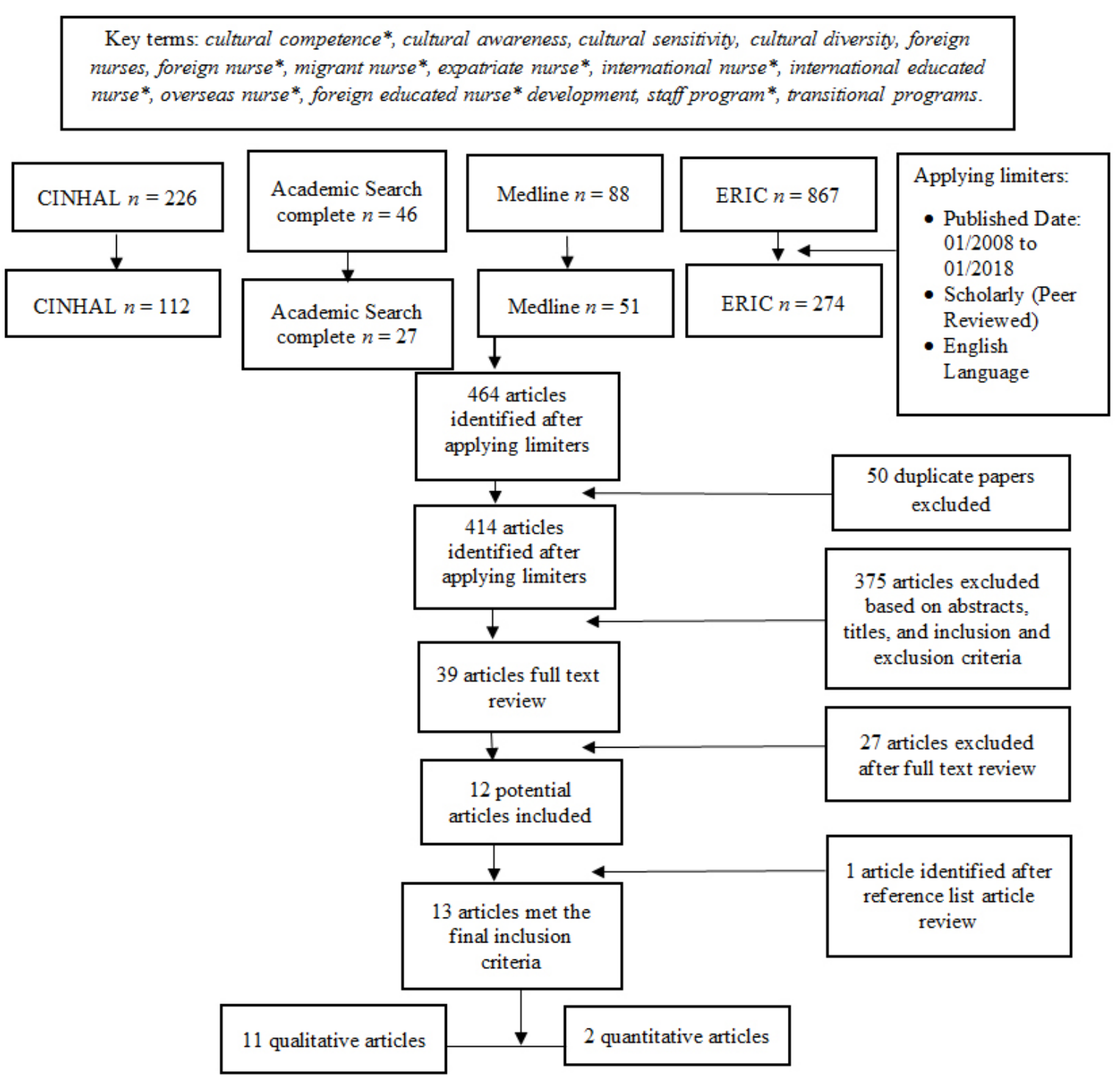

Figure 1. Literature search strategy and outcomes 


\subsection{Communication}

Verbal and non-verbal communication can be positive or negative and, therefore, produce either positive or negative outcomes in the nursing workplace. When migrant nurses commence work in a foreign environment, they are often perceived as unsafe ${ }^{[14]}$ and less clinically able due to their lack of effective communication skills. ${ }^{[13,15-18]}$ As a result, migrant nurses feel disempowered. ${ }^{[13]}$ Disempowerment may also occur due to perceived discrimination and others negative attitudes. Verbal communication factors include language barrier, accent and slang, and style of speaking while non-verbal communication is related to gestures

\subsubsection{Language barrier}

The biggest challenge that migrant nurses face is the language barrier. ${ }^{[15]}$ Having inadequate knowledge of the host country's language can be frustrating. ${ }^{[14,19]}$

\subsubsection{Accent and slang}

An individual's accent ${ }^{[20-22]}$ and use of jargon and slang ${ }^{[20]}$ may lead to misunderstandings, offense being taken, and miscommunication of patient information. ${ }^{[18]}$

\subsubsection{Style of speaking}

Different styles of speaking, which arise from cultural and personality differences, can cause misunderstandings, ${ }^{[18]}$ such as speaking assertively. ${ }^{[22]}$ Even the use of words like please and thank you can cause problems; their omission or inappropriate use can be seen as impoliteness in some cultures. ${ }^{[20]}$

\subsubsection{Gestures}

Migrant nurses try to overcome language barriers using nonverbal methods, such as gestures. However, gestures often have different meanings in different cultures and can lead to a nurse giving offense to others. ${ }^{[13]}$ For example, while avoiding eye contact may be seen as respectful in one culture, it may be seen as a sign of dishonesty in another. ${ }^{[20]}$

\subsection{Religion and spirituality}

A key component of any culture is religion and spirituality. Nurses' cultural competence in this component is related to non-Muslim nurses working in a Muslim culture and religious nurses working in a non-religious culture.

\subsubsection{Nurses working in a Muslim culture}

For nurses moving to a Muslim culture, it is necessary for them to understand the role of Islam since it pervades all aspects of life including healthcare. Al-Yateem et al. reported that migrant nurses in Saudi Arabia or the UAE, who had limited knowledge of Islamic culture, felt anxious about how they could integrate their patients' religious requirements into the care schedule. Others, who thought they knew something about Islam, found their knowledge to be incorrect. ${ }^{[14]}$
Nurses need to have specific religious knowledge when dealing with Muslim patients; for example, females should only be cared for by female healthcare staff. ${ }^{[15]} \mathrm{Al}$-Yateem et al. noted several challenges to care provision, including the integration of prayer times into care routines. These authors also found that fasting during Ramadan is challenging because some of the rituals interfere with care programs. Migrant nurses may not understand why sick Muslim patients want to fast. Furthermore, end-of-life practices, such as the decision not to resuscitate, are different in Muslim countries. ${ }^{[14]}$

\subsubsection{Nurses working in a non-religious culture}

In countries like the UK, where religion is less obvious, nurses must give care in a non-judgemental way. While they need to be aware that anyone may require support during end-of-life care, nurses cannot talk about religion with their patients in these countries. ${ }^{[20]}$ The "low emphasis on religion" challenged migrant nurses and made it difficult for them to offer end-of-life support. ${ }^{[20]}$

\subsection{Customs}

Nurses working in a different culture have to adapt to different social customs, such as the use of titles, gender roles, familial structure, healthcare practices, and expressions of grief.

\subsubsection{Titles}

New migrant nurses in Western countries may find themselves in a less formal society than their own leading to feeling of cultural shock. For example, nurses from Ghana and the Philippines said first names can only be used by close friends and family in their society; whereas, a formal style using a title like $\mathrm{Mr}$ or Mrs is required for a senior at work or a client. ${ }^{[20]}$

\subsubsection{Gender roles}

Some nurses find caring for patients of the opposite sex difficult due to their own cultural customs which view this unfavourably. ${ }^{[21]}$

\subsubsection{Familial structure}

Perhaps the most challenging social customs to deal with are the ones concerning families. Migrant nurses in the UK noticed that relatives usually phone rather than visit the hospital. ${ }^{[20]}$ However, in other cultures, several family members may visit a patient all at the same time. ${ }^{[13,14,23]}$ In some cultures, the senior male is the decision maker for all members of the extended family, and the oldest son takes over this role in his absence. ${ }^{[14]}$ Such situations can result in changes in care preferences. ${ }^{[15]}$ In some cultures, a family will take part in caring for an admitted patient, ${ }^{[19]}$ such as in India, China, and the Philippines, ${ }^{[21]}$ but rarely in the USA. ${ }^{[19]}$ 


\subsubsection{Healthcare practices}

Conflict during care encounters may result from nurses' and patients' varying beliefs about the causes and treatments of illness. ${ }^{[14]}$ Okougha \& Tilki stressed that it is essential for nurses not to place their own healthcare values onto those of their clients to avoid stereotyping or ethnocentrism. ${ }^{\text {[20] }}$ Sidumo et al. found that migrant nurses in Saudi Arabia did not know about the use of traditional herbal remedies, role of a spouse, nor disposal of the placenta following birth. ${ }^{[23]}$

\subsubsection{Expressions of grief}

Expressions of grief differ greatly from culture to culture. For example, migrant Turkish nurses in the UK found it difficult to accept that "private, controlled emotion [of British people] is no less heartfelt" than grief shown in "overt and expressive [in Turkish culture]". [20]

\subsection{Work environment}

Migrant nurses' cultural competence within the work environment is affected by transition between healthcare systems and by changes in the nurse's role.

\subsubsection{Transition between healthcare systems}

For example, nurses may face challenges adapting to the structure of the U.S. healthcare system and living in a capitalist culture. ${ }^{[22]}$ Some migrant nurses feel hospitals are more concerned about meeting budget demands than offering optimal care. ${ }^{[18,22]}$ Okougha and Tilki found that nurses from countries with no healthcare system found the concept of a healthcare system, like the British National Health Service, difficult to grasp. ${ }^{[20]}$

\subsubsection{Nurses' roles}

Nurses report differences in the autonomy of their roles. ${ }^{[21,24,25]}$ Ho reported that contrary to their home countries where physicians made all care decisions, migrant nurses needed to participate or often make decisions autonomously in the new country. ${ }^{[25]}$ Lack of confidence to practice autonomously can be a serious drawback to the success of migrant nurses in the USA. ${ }^{[18]}$

\section{Discussion}

The purpose of this literature review was to identify the cultural competence learning needs of migrant nurses. These needs include communication, religion and spirituality, customs, and the work environment. As such learning needs will differ depending on each national context, cultural competency training for migrant nurses would need to be customized.

\subsection{Communication}

Communication was most frequently connected with a lack of cultural competence in the reviewed literature. These findings were echoed by other authors where miscommunication and language barriers lead to misunderstandings. Canadian researchers also reported that language was one of the biggest barriers to migrant nurses' successful integration into Canada's healthcare workforce. ${ }^{[26,27]}$

Having a strong accent may be another barrier as it often leads to confusion and perception of nurse's incompetence. Other researchers have reported similar findings. ${ }^{[27,28]}$ For example, Lum et al. reported that a strong English language accent caused problems for migrant nurses in Canada. Moreover, misunderstandings are caused by both migrant's and local nurses' lack of knowledge of local medical terminology. [27]

Studies in this literature review described how the use of certain gestures offended other staff and patients. Smith noted similar problems with non-verbal communication in his study of migrant nurses in the USA. ${ }^{[29]}$

It was found in this literature review that migrant nurses' poor communication skills lead to a feeling of disempowerment, which was believed to negatively affect patient safety. This finding was supported in similar studies. Parrone et al. found migrant nurses' poor communication skills resulted in a lack of confidence, which often silenced them and caused others not to know if they had been understood or possibly ignore them in the future. ${ }^{[28]}$ Pung and Goh mentioned that migrant nurses felt demeaned when communicating on the phone due to their lack of confidence in their speaking ability. ${ }^{[30]}$ This can lead not only to stress but also self-doubt in migrant nurses' own abilities. ${ }^{[31]}$

\subsection{Religion and spirituality}

Non-Muslim nurses working in Islamic countries could find their lack of knowledge of Islam an obstacle to providing competent care. In a study of migrant nurses working in Saudi Arabia, Marrone noted that migrant nurses learned that Muslim patients had to be ritually clean before praying, needed help to face Mecca if necessary, and preferred the environment to be quiet during prayer times. The nurses in this study also had to learn that Muslims use the expression Inshallah (God willing) when referring to future possibilities as humans do not have the certainty of future occurrences. ${ }^{[32]}$ Furthermore, Lovering explained how Islam teaches beliefs of predestination, so illness and cure is the will of Allah and Muslims are encouraged to seek medical treatment while at the same time apply spiritual Islamic healing rituals. In this literature review, it was evident that the apparent lack of religious belief in the host country was confusing to religious migrant nurses working in secular Western countries. ${ }^{[33]}$ Pung and Goh attributed this "culture shock" to the absence of 
familiar cultural signs such as religion. ${ }^{[30]}$

Although spirituality is often associated with religion, the WHO stated that spiritual care, including giving comfort and physical touch, is essential for all patients. ${ }^{[34]}$ Kaddourah et al. suggested that migrant nurses' flexibility and understanding while dealing with challenging religious situations is an important aspect of achieving cultural competence. ${ }^{[34]}$ Studies in this literature review highlighted how end-of-life practices differed between cultures and posed moral dilemmas for some nurses. Halligan supported this concept when noting that migrant nurses from western countries in Saudi Arabia found it stressful to continue to care for brain-dead patients as it was their belief that a patient's life should not be unnecessarily prolonged. ${ }^{[35]}$

\subsection{Customs}

One crucial custom described in this literature review that nurses need to be aware of is the role of gender in the host country. For example, in Arabic countries, it is preferred that a nurse of the same sex as the patient provides care for the patient. However, Halligan reported that it is not always possible, which is something that migrant nurses in Saudi Arabia found stressful and challenging. ${ }^{[35]}$

Studies in this literature review also illustrated how a family's role during illness varies from culture to culture. In a study of non-Muslim nurses working in Saudi Arabia, a list of customs concerning Muslim families that non-Muslims should know in order to give culturally competent care was identified. ${ }^{[36]}$

Regarding health care practices, understanding and acceptance of traditional care practices in the host country, such as using herbal remedies and cupping, also helps to avoid ethnocentrism. ${ }^{[33]}$

\subsection{Work Environment}

The findings of this literature review suggested that migrant nurses often face difficulty in transitioning, particularly with differences in healthcare systems and organizational cultures. This indicates the need for cultural competence learning to extend to every facet of being a migrant nurse such as assisting migrant nurses understand the health care system. Newton et al. stated that nurses moving to the USA could have problems transitioning when unfamiliar with the U.S. healthcare system, such as laws of confidentiality and other medico-legal components. ${ }^{[11]}$ Migrant nurses in the USA were not aware of the importance placed on teamwork and collaboration and the need to be assertive which differed from the hierarchical systems in their home countries. ${ }^{[37]}$

In this literature review, the reported role of migrant nurses differed from home to host country with different duties and level of autonomy. In Canada, migrant nurses reflected on how their professional role was different in the host country than their home specifically related to advocacy and degree of autonomy. ${ }^{[24]}$ This was evident in other studies. Migrant nurses in Australia described how they had to wash and feed patients; whereas, in their home countries, families deal with this aspect of care. ${ }^{[38]}$ Furthermore, migrant nurses working in Saudi Arabia felt anxious when they were expected to transcribe medicine, which was forbidden in their home country. ${ }^{[39]}$ With an increased level of autonomy, migrant nurses in the USA are able to take part in the decision-making process but are also accountable for their actions. ${ }^{[29]}$

\subsection{Strengths and limitations}

The strengths and limitations of this literature review are related to the included articles. The findings in these articles are relevant for informing the development of an educational program as these articles were published within the last 10 years between 2008 and 2018. However, educational programs for migrant nurses in a particular host country or organization would have to be customized according to the nurses' specific needs. In addition, while most studies had a high level of quality according to the MMAT tool, those with lower than $100 \%$ quality were included in the analysis as their results were similar to those with higher quality appraisal. Furthermore, some relevant articles were possibly missed during the database search process because the search was limited to specific terms. Most studies in this literature review used a qualitative method; however, a balance between qualitative and quantitative methods might have produced more factual outcomes.

\section{CONCLUSION AND RECOMMENDATIONS}

This literature review was carried out to identify the cultural competence needs of migrant nurses in order to inform educational programs addressing these needs. Cultural competence improves staff satisfaction and quality of patient care. Cultural competence was found to be related to communication, religion and spirituality, customs, and work environment. Language barrier was the biggest obstacle to communication, which included nurses' low language level, strong accent, and lack of knowledge of medical terminology. The major issues relating to religion and spirituality were the different religious beliefs between nurse and client and the often limited knowledge that nurses held about their clients' religions. Differences in cultural customs between nurses and patients also caused misunderstandings in many settings. Moving from one work environment to another was difficult for many nurses due to different role expectations and work environments. The results of this literature review highlight the need 
to identify the unique cultural competence needs of migrant nurses at different cultural settings. This could be used to inform the development of educational programs that aim to address cultural competence in practice settings with migrant nurses. Future research should also assess the outcomes of providing cultural competence interventions that address communication, religion and spirituality, customs, and work environment of the host country. Such studies may use mixed

\section{REFERENCES}

[1] Leininger M. What is transcultural nursing and culturally competent care? Commentaries: Defining transcultural nursing. Journal of Transcultural Nursing. 1999; 10(1): 9. PMid:10476143. https://doi.org/10.1177/104365969901000105

[2] Leininger M. Transcultural nursing research to transform nursing education and practice: 40 years. Image: Journal of Nursing Scholarship. 1997; 29(4): 341-347. PMid:9433006. https ://doi .org/10 .1111/j.1547-5069.1997.tb01053.x

[3] Dauvrin M, Lorant V. Leadership and cultural competence of healthcare professionals: a social network analysis. Nursing Research. 2015; 64(3): 200-210. PMid:25871625. https://doi.org/10.1 097/NNR . 0000000000000092

[4] Gower S, Duggan R, Dantas JAR, et al. One Year On: Cultural Competence of Australian Nursing Students Following International Service-Learning. Journal of Nursing Education. 2019; 58(1): 17-26. PMid:30673088. https : //doi .org/10.3928/01484834-20190 103-04

[5] Benbenishty J, Gutysz WA, Harth I, et al. The migrant crisis and the importance of developing cultural competence in the intensive care unit. Nursing in Critical Care. 2017; 22(5): 262-263. PMid:28834030. https://doi.org/10.1111/nicc.12313

[6] Weber O, Sulstarova B, Singy P. Cross-Cultural Communication in Oncology: Challenges and Training Interests. Oncology Nursing Forum. 2016; 43: E24-E33. PMid:26679454. https ://doi.org/ 10.1188/16. ONF.E24-E33

[7] Schmidt NC, Fargnoli V, Epiney M, et al. Barriers to reproductive health care for migrant women in Geneva: a qualitative study. Reproductive Health. 2018; 15: 1. PMid:29510718. https ://doi .org/ 10.1186/s12978-018-0478-7

[8] Truong M, Paradies Y, Priest N. Interventions to improve cultural competency in healthcare: A systematic review of reviews. BMC Health Services Research. 2014; 14: 99. PMid:24589335. https : //doi.org/10.1186/1472-6963-14-99

[9] Peláez S, Hendricks KN, Merry LA, et al. Challenges newly-arrived migrant women in Montreal face when needing maternity care: Health care professionals' perspectives. Globalization \& Health. 2017; 13: 1-9. PMid:28122630. https://doi.org/10.1186/s1 2992-016-0229-x

[10] Newton S, Pillay J, Higginbottom G. The migration and transitioning experiences of internationally educated nurses: a global perspective. Journal of Nursing Management. 2012; 20(4): 534-550. PMid:22591155. https://doi.org/10.1111/j.1365-2834. 20 $11.01222 . \mathrm{x}$

[11] Cronin P, Ryan F, Coughlan M. Undertaking a literature review: A step-by-step approach. British Journal of Nursing. 2008; 17(1): method research design to capture results that provide a comprehensive understanding of the phenomenon. As achieving cultural competence is a life-long journey, longitudinal studies are also warranted to provide better understanding of how these skills could be developed among migrant nurses as they settle in the host countries.

\section{CONFlicts OF InTEREST Disclosure}

The authors declare no conflicts of interest.
38-43. PMid:18399395. https://doi.org/10.12968/bjon. 20 08.17 .1 .28059

[12] Pace R, Pluye P, Bartlett G, et al. Testing the reliability and efficiency of the pilot Mixed Methods Appraisal Tool (MMAT) for systematic mixed studies review. International Journal of Nursing Studies. 2011; 49(1): 47-53. PMid:21835406. https://doi.org/10.1016/j.ij nurstu. 2011.07.002

[13] Almutairi AF, McCarthy A, Gardner GE. Understanding Cultural Competence in a Multicultural Nursing Workforce: Registered Nurses' Experience in Saudi Arabia. Journal of Transcultural Nursing. 2015; 26(1): 16-23. PMid:24626280. https://doi.org/10 $.1177 / 1043659614523992$

[14] Al-Yateem N, AlYateem S, Rossiter R. Cultural and religious educational needs of overseas nurses working in the Kingdom of Saudi Arabia and the United Arab Emirates. Holistic Nursing Practice. 2015; 29(4): 205-215. PMid:26086464. https://doi.org/10.1 097/HNP.0000000000000095

[15] Aboshaiqah AE, Tumala RB, Inocian EP, et al. Enhancing culturally competent nursing care in Saudi Arabia. Journal of Cultural Diversity 2017; 24(1): 20-26.

[16] Rodriguez G, Muaoz A, Hoga LA. Cultural experiences of immigrant nurses at two hospitals in Chile. Revista Latino-Americana De Enfermagem (RLAE). 2014; 22(2): 187-196. PMid:26107824. https://doi.org/10.1590/0104-1169.2980.2401

[17] Stubbs F. Recruitment of nurses from India and their experiences of an overseas nurses program. Nursing in Critical Care. 2017; 22(3): 176-183. PMid:26095166. https://doi.org/10.1111/nicc.1 2181

[18] Thekdi P, Wilson BL, Wu Y. Recruitment \& retention report. Understanding post-hire transitional challenges of foreign-educated nurses. Nursing Management. 2011; 42(9): 8-14. PMid:21873842. https : //doi.org/10.1097/01. NUMA.0000403285.34873.c7

[19] Liou S, Cheng C. Experiences of a Taiwanese nurse in the United States. Nursing Forum. 2011; 46(2): 102-109. PMid:21517883. https://doi.org/10.1111/j.1744-6198.2011.00211.x

[20] Okougha M, Tilki M. Experience of overseas nurses: the potential for misunderstanding. British Journal of Nursing. 2010; 19(2): 102 106. PMid:20220647. https://doi.org/10.12968/bjon. 2010 .19 .2 .46293

[21] Sherman R, Eggenberger T. Transitioning internationally recruited nurses into clinical settings. Journal of Continuing Education in Nursing. 2008; 39(12): 535-568. PMid:19110728. https ://doi.org/ 10.3928/00220124-20081201-03

[22] Wolcott K, Llamado S, Mace D. Integration of internationally educated nurses into the U.S. workforce. Journal for Nurses in Pro- 
fessional Development. 2013; 29(5): 263-268. PMid:24060663. https://doi.org/10.1097/01.NND.0000433145.43933.98

[23] Sidumo E, Ehlers V, Hattingh S. Cultural knowledge of non-Muslim nurses working in Saudi Arabian obstetric units. Curationis. 2010; 33(3): 48-55. PMid:21428239. https://doi.org/10.4102/cu rationis.v33i3.7

[24] Neiterman E, Bourgeault IL. Cultural competence of internationally educated nurses: Assessing problems and finding solutions. Canadian Journal of Nursing Research. 2013; 45(4): 88-107. PMid:24617282. https://doi.org/10.1177/084456211304500408

[25] Ho YC. Investigating internationally educated Taiwanese nurses' training and communication experiences in the United States. Journal of Continuing Education in Nursing. 2015; 46(5): 218-227. PMid:25955425. https://doi .org/10.3928/00220124-20150 420-02

[26] Crawford T, Candlin S, Roger P. New perspectives on understanding cultural diversity in nurse-patient communication. Collegian. 2017; 24(1): 63-69. PMid:29218964. https://doi.org/10.101 6/j.colegn.2015.09.001

[27] Lum L, Dowedoff P, Bradley P, et al. Challenges in oral communication for internationally educated nurses. Journal of Transcultural Nursing. 2015; 26(1): 83-91. PMid:24821518. https: //doi.org/10.1177/1043659614524792

[28] Parrone J, Sredl D, Donaubauer C, et al. Charting the 7 c's of cultural change affecting foreign nurses: Competency, communication, consistency, cooperation, customs, conformity and courage. Journal of Cultural Diversity. 2008; 15(1): 3-6. https://doi .org/10.1016/ j.teln.2007.09.002

[29] Smith CD, Ho JO. How to positively integrate internationally educated nurses. Nursing Management. 2014; 45(6): 30-36. PMid:24871290. https://doi.org/10.1097/01. NUMA.000044 9761.61253.a7

[30] Pung L, Goh Y. Challenges faced by international nurses when migrating: an integrative literature review. International Nursing Review. 2017; 64(1): 146-165. PMid:27501277. https ://doi.org/10.1 111/inr. 12306

[31] Primeau M, Champagne F, Lavoie-Tremblay M. Foreign-trained nurses experiences and socio professional integration best prac- tices. Health Care Manager. 2014; 33(3): 245-253. PMid:25068879. https://doi.org/10.1097/HCM.0000000000000018

[32] Marrone SR. The art of knowing: Designing a nursing professional development program based on American nurses' experiences of providing care to Arab Muslims. Journal of Nursing Education and Practice. 2017; 7(7): 104. https://doi.org/10.5430/jnep.v 7n7p104

[33] Lovering S. The crescent of care: a nursing model to guide the care of Arab Muslim patients. Diversity \& Equality in Health \& Care. 2012; 9(3): 171-178.

[34] Kaddourah B, Abu-Shaheen A, Al-Tannir M. Nurses' perceptions of spirituality and spiritual care at five tertiary care hospitals in Riyadh, Saudi Arabia: A Cross-sectional study. Oman Medical Journal. 2018; 33(2): 154-158. PMid:29657685. https://doi .org/10.5001/om j.2018.28

[35] Halligan P. Caring for patients of Islamic denomination: Critical care nurses' experiences in Saudi Arabia. Journal of Clinical Nursing. 2006; 15(12): 1565-1573. PMid:17118079. https : //doi.org/10.1111/j.1365-2702.2005.01525.x

[36] Al Mutair AS, Plummer V, O'Brien AP, et al. Providing culturally congruent care for Saudi patients and their families. Contemporary Nurse: A Journal for the Australian Nursing Profession. 2014; 46(2): 254-258. PMid:24787260. https://doi.org/10.5172/conu. 2 014.46 .2 .254

[37] Case DL, Dickerson PS, Lubejko BG. Providing continuing education for international nurses. Journal of Continuing Education in Nursing. 2015; 46(10): 428-430. PMid:26430858. https://doi. org/10.3928/00220124-20150918-11

[38] Xiao LD, Willis E, Jeffers LFactors affecting the integration of immigrant nurses into the nursing workforce: A double hermeneutic study. International Journal of Nursing Studies. 2014; 51(4): 640-653 PMid:24016598. https://doi.org/10.1016/j.ijnurstu. 201 3.08 .005

[39] van Rooyen D, Telford-Smith C, Strümpher J. Nursing in Saudi Arabia: Reflections on the experiences of South African nurses. Health SA Gesondheid. 2010; 15(1): 1-9. https://doi.org/10.4102/ hsag.v15i1.500 